\title{
High pressure investigations on fluid system - A challenge to experiment, theory and application
}

\author{
Gerhard M. Schneider \\ Lehrstuhl fur Physikalische Chemie II, Fakultat far Chemie, Ruhr-
} Universitat Bochum, D-4630 Bochum 1, Federal Republic of Germany

\begin{abstract}
In the present lecture some activities of the author's group on the thermodynamics and dynamics of pure and mixed fluids under high pressure will be reviewed.

First the complex dependences of liquid-liquid, liquid-gas and gas-gas equilibria and the related critical phenomena on pressure will be considered, and it will be shown on recent data up to about $300 \mathrm{MPa}$ that continuous transitions exist between these different types of phase equilibrium in fluid mixtures. For some alkanol mixtures the concentrations of the monomeric and associated alkanol species in the coexisting phases have been determined separately by near-infrared spectroscopy (NIR).
\end{abstract}

Some applications will be briefly described e.g. In supercritical fluid extraction (SFE) of low-volatile and/or thermolabile substances and recent high-pressure results will be presented for some ternary and quaternary systems being of interest for the use of low-volatile moderators in SFE. Analytical separations using supercritical fluid chromatography (SFC) and the determination of some physicochemical properties (e.g. capacity ratios, binary diffusion coefficients) from constant-density or density-programmed SFC runs will also be considered.

The kinetics of phase separation in fluid mixtures has been studied using pressure-jump and other transient techniques. Here the accent is on the investigation of (nearly) isopycnic fluid systems (e.g. methanol+cyclohexane) in order to simulate microgravity conditions.

Finaliy the effect of pressures up to about $2 \mathrm{GPa}$ on the mesomorphic phase stability of some selected thermotropic liquid crystals will be demonstrated using differential thermal analysis (DTA) and diamond anvil cell (DAC) techniques.

\section{INTRODUCTION}

Liquid states can be approached on different ways, e.g. for a simple pure component from low pressures via liquid-gas equilibria, from low temperatures via solid phases and from high temperatures via gas-liquid equilibria or critical and supercritical states.

The present review considers two more sophisticated ways of approach to isotropic liquid states both involving high pressures (see Fig. 1):

- the first way (for mixtures) starting at (relatively) high temperatures in the supercritical one-phase region going via fluid phase equilibria and their related critical phenomena and

- the second way (for a pure component) starting at (relatively) low temperatures from a solid phase going via liquid crystalline states.

Considering the first way the stability ranges of liquid phases are limited to higher temperatures by the critical region. For a pure substance (e.g. carbon dioxide) the vapour pressure curve $1 \mathrm{~g}$ ends at the gas-liquid critical point $C P$ where the coexisting liquid and gaseous phases become identical. In Sections 4 and 5 of the present review it will be explained on some characteristic examples how the critical parameters will be influenced by the addition of one or even more substances. Such mixtures are of interest for fundamental research and theory as well as for some applications e.g. In Supercritical Fluid Extraction (SFE) and Supercritical Fluid Chromatography (SFC) (see Section 6). It should be mentioned that several preceding Rossini Lectures were concerned with related problems e.g. that of M.L. McGlashan (ref. l) with details of the gas-liquid critical curves in binary mixtures, 
that of E.U. Franck (ref. 2) with high-pressure high-temperature effects and critical states predominantly in aqueous solutions and that of K.S. Pitzer (ref. 3) with the theoretical description of these and other critical phenomena.

Considering the second way it has to be taken into account that for a large and important class of substances the melting transition is effectuated via anisotropic liquid crystalline states exhibiting different degrees of positional disorder where, however, a considerable amount of orientational order is remaining. In Section 7 some interesting high-pressure phenomena of these substances are very shortly reviewed. Orientationally disordered molecular crystals (ODMC) that also exhibit important transition states between solids and liquids are not considered here; they have been discussed in detail elsewhere (see e.g. ref. 4).

It has, however, to be accentuated that the phenomena described in this paper can only be treated on some selected examples. For details the reader is referred to several other reviews of the author (ref. 5-21). The present review is a summary and an extension of earlier review papers (e.g. ref. 15, 18, 19) considering some more recent, mostly unpublished work that has been effectuated in the author's group at the University of Bochum during the last years; for a list of references concerning recent publications see ref. 22 .

\section{LIQUID-LIQUID PHASE EQUILIBRIA IN SOME BINARY AND TERNARY SYSTEMS: RECENT RESULTS ON SOME SELECTED SYSTEMS}

The pressure dependence of the liquid-liquid critical phase behaviour of binary mixtures has been extensively discussed in several preceding review papers (ref. 5-7, 9); for experimental techniques and set-ups see e.g. ref. 16.

As a simple but characteristic example isobaric $T(x)$ sections for the system pentane + methanol according to synthetic measurements by Haarhaus (ref. 23) are presented in Fig. 2a. This system exhibits upper critical solution temperatures (UCSTs) that rise with increasing pressures i.e. $\mathrm{dT} / \mathrm{dp}$ is positive. Since (with some important simplifications; see ref. 5, 9) the molar excess enthalpy $\mathrm{H}_{\mathrm{C}}^{\mathrm{E}}$ will normally be positive at an UCST it follows from a more detailed thermodynamic discussion that for $\mathrm{dT} / \mathrm{dp}>0$ the molar excess volume $v^{\mathrm{E}}$ will also be positive. This is demonstrated in Fig. $2 b$ where $V^{E}$ is plotted against mole fraction $x$ for pressures up to $140 \mathrm{MPa}$ at a constant temperature of $308.15 \mathrm{~K}$; the data were obtained by direct measurements of the volume change in mixing $\Delta V_{\text {under }}$ pressure by Grasedieck (ref. 24). As expected $V_{m}^{E}$ is positive and the experimental $V^{E}$ data points are lying on straight lines within the miscibility gap (see isobars at 100,120 and $140 \mathrm{MPa}$ in Fig. $2 \mathrm{~b}$ ).

Especially interesting pressure dependences have been found for mixtures exhibiting closed miscibility gaps in isobaric $T(x)$ sections (see ref. 5-7, 9). In Fig. 3a a closed loop is schematically shown that disappears with increasing pressure at a socalled hypercritical point HPl (type 1). It may reappear again at still higher pressures at another hypercritical point HP2 (type $1^{\prime}$ ) or the closed loop only shrinks and then increases again with rising pressure (type 2). With similar simplifications such as mentioned above, $\mathrm{H}^{2}$ should change its sign from minus to plus with increasing temperature at constant pressure and $V_{m}^{E}$ from minus to plus with increasing pressure at constant temperature in these systems. Examples have been found e.g. in methylpyridine + water systems; they have been discussed in detail elsewhere (ref. 5-7, 9).

Systems showing a critical phase behaviour according to types 1 and $I^{\prime}$ are completely miscible at temperatures and pressures between HPl and HP2 e.g. 3-methylpyridine $+\mathrm{D}_{2} \mathrm{O}$ or $3-$ methylpyridine $+\mathrm{H}_{2} \mathrm{O}+\mathrm{a}$ small amount of $\mathrm{Na}_{2} \mathrm{SO}_{\text {added }}$ (ref. 5-7, 9, 25). For the latter system binary diffusion coefficients $D_{12}$ are plotted in Fig. $3 \mathrm{~b}$; they were measured by Quednau (ref. 26) using photocorrelation spectroscopy. The $\mathrm{D}_{12}$ values decrease when both HP1 or HP2 are approached respectively; this is in qualitative agreement with theory according to which $\mathrm{D}_{12}=0$ at a critical point.

Recent measurements by Ochel (ref. 27) on butanol + water mixtures where also closed loops exist are shown in Fig. 4. For 2-butanol $+\mathrm{H}_{2} \mathrm{O}$ a pressure maximum on the critical curve at about $340 \mathrm{~K}$ and $90 \mathrm{MPa}$ that was already known from earlier experiments (ref. 5-7, 9) has been confirmed in the present measurements as well as an additional pressure minimum on the low-temperature branch of the critical curve giving rise to additional UCSTs at rather low temperatures. These s-shaped critical curves are also found for aqueous mixtures of 2butanol containing small amounts of 2-methyl-2-propanol (tertiary butanol) or 1-butanol respectively. At higher 1-butanol contents of the 2-butanol the pressure minimum 1s not longer detectable. At higher pressures lower critical solution temperatures LCSTs are also found for the 1-butanol $+\mathrm{H}_{2} \mathrm{O}$ sytem in the low-temperature range that have been unknown up to now. The consequence is that the binary system 1-butanol $+\mathrm{H}_{2} \mathrm{O}$ also exhibits a closed loop at high pressures corresponding to type 2 of Fig. $3 \mathrm{a}$. New investigations are underway where similar immiscibility phenomena are produced by the addition of in-salting and outsalting electrolytes to butanol + water mixtures. S-shaped critical curves such as shown in 
F1g. 4 play an important role in a classification of closed loop systems presented recently by Mazur and Boshkov (ref. 54 ).

\section{PRESSURE-JUMP RELAXATION EXPERIMENTS ON FLUID SYSTEMS}

Since about fifteen years pressure-jump relaxation and other transient techniques are used in the author's group for investigations on the kinetics of chemical reactions and phase formation in fluid systems. In a review (ref. 28) the experimental methods and set-ups used have been described and some selected results presented for the period till 1987 ; here also details and references are given. In the present paper only some very recent developments are treated the accent being on results that are of interest for microgravity research.

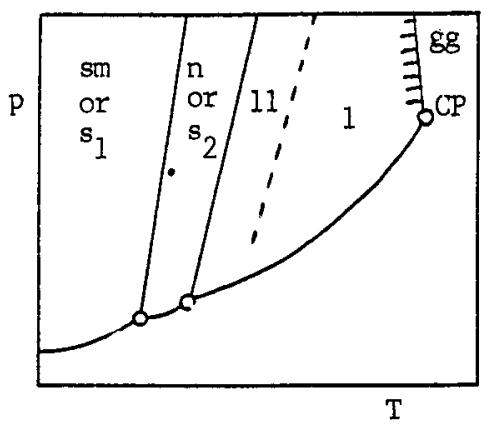

Fig. 1. $p(T)$ projection of the phase diagram of a pure component or a binary system respectively (schematically, not complete; ref. 15; see text)
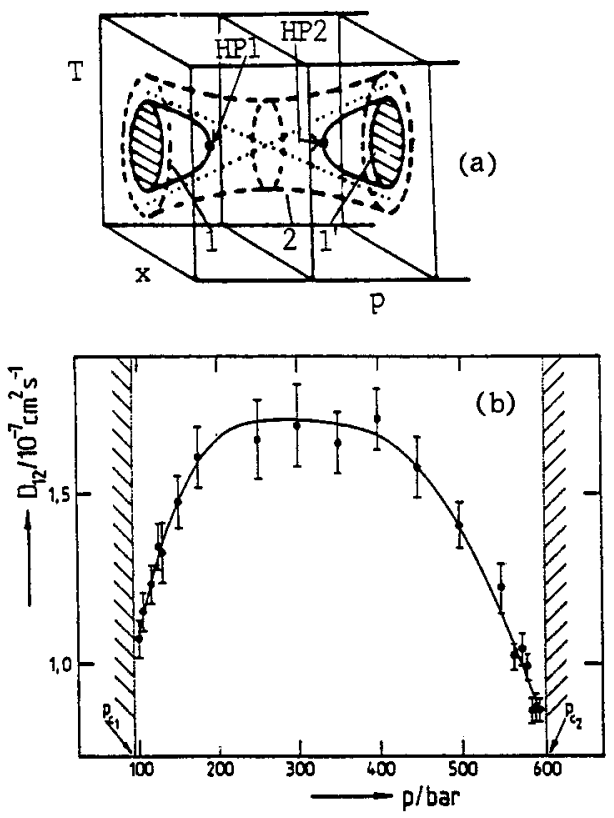

Fig. 3. Closed $T(x)$ miscibility loops at high pressures

a. pTx phase diagrams (schematically; ref. 5-7, 9, 25; see text) b. Binary diffusion coefficients $\mathrm{D}_{12}$ of the system 3-methylpyridine + water $+\mathrm{Na}_{2} \mathrm{SO}_{4}$ at $351.2 \mathrm{~K}$ using photocorrelation spectroscopy

(Quednau, ref. 26)
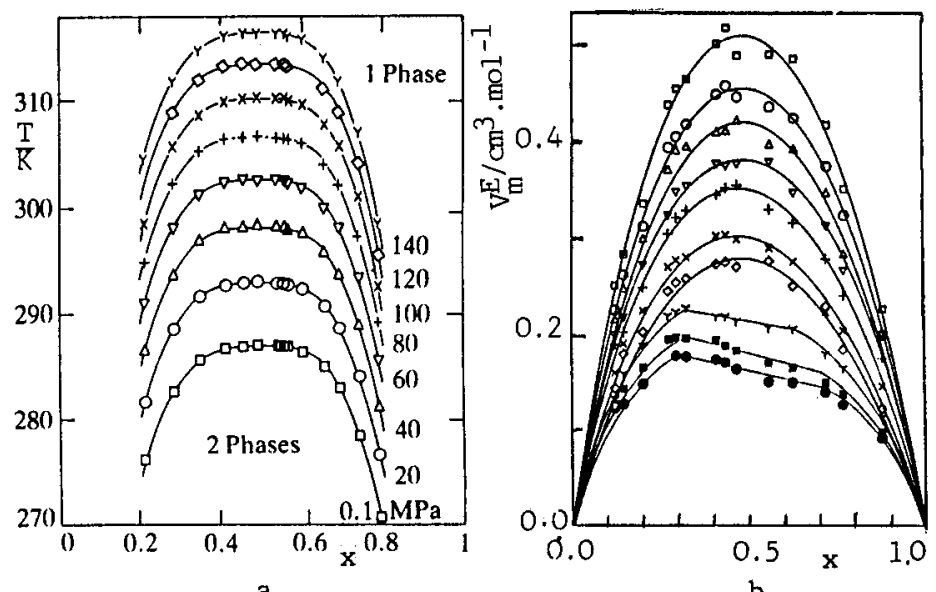

Fig. 2. High-pressure experiments on pentane $+\mathrm{CO}_{2}$ a. $T(x)$ isobars $(x=x$ (methanol);

Haarhaus et al., ref. 23)

b. $V_{\mathrm{m}}^{\mathrm{E}}(\mathrm{x})$ curves at $\mathrm{T}=$ const $=308.15 \mathrm{~K}$

( $x=x$ (pentane); from above $0.1,10,20,30,40,60$, $80,100,120$ and $140 \mathrm{MPa}$; Grasedieck, ref. 24)

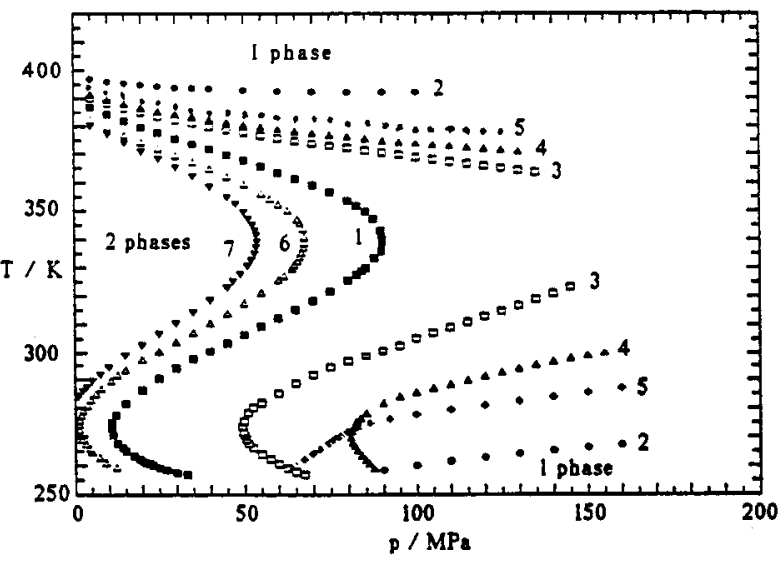

Fig. 4. Liquid-liquid equilibria in butanol + water mixtures at high pressures $(1=2$-butanol + water, $2=1$-butanol + water, $3=2$-butanol + 1-butanol $(80: 20)+$ water, $4=2-$ butanol + 1-butanol $(70: 30)+$ water, $5=2$-butanol + 1-butanol $(60: 40)+$ water, $6=2$-butanol + t-butanol $(95: 5)+$ water, $7=2$-butanol + t-butanol $(90: 10)+$ water; for all curves $\times$ (water $) \approx$ const $=0.88 \pm 0.02$; Ochel, ref. 27) 
In Fig. 5 a schematical three-dimensional pressure-temperature-molefraction phase diagram is shown for the system cyclohexane + methanol. This system that exhibits upper critical solution temperatures (UCSTs) rising with increasing pressure has a quite unique property: The densities $\rho$ ' and $\rho$ " of the coexisting phases ' and "are rather accurately the same and can even be perfectly balanced by using deuterated cyclohexane or very small amounts of an adequate additive. Consequently layering of the demixed phase in the earth's gravitational field does not occur or is considerably slowed down. As a consequence microgravity conditions can be simulated and phenomena studied that would otherwise only be detectable in space e.g. In a space shuttle or in a rocket. In Fig. 5 it is also indicated by an arrow how heterogeneous states are attainable very rapidly by a pressure jump into the two-phase region.

Several cells for such measurements have been described in the review mentioned above (ref. 28). A more recent version of one of these cells is shown in Fig. 6 (ref. 29). Here a thin layer (about $1 \mathrm{~mm}$ thick) of the fluid system under test is positioned between two sapphire windows that can be thermostatted separately by pumping water through the hollow spaces in the nuts, the nuts being closed with glass windows; thus different (positive or negative) temperature gradients can be applied to the layer. Originally this cell was constructed for negative pressure jumps using the bursting membrane principle well-known from investigations on fast chemical reactions. Since in the present case positive pressure jumps are neccesary to penetrate the two-phase region the pressure is rapidly increased by opening an electrical valve between the cell and a buffer volume maintained at higher pressure. The state of the layer after the jump is documented as a function of time by video or photography.

Some characteristic results are presented in Fig. 8. For the system shown in Fig. 8a (ref. 29 , 30) the temperature gradient between the upper and the lower window was negative and convection already existed before the pressure jump where the flow, however, was invisible. By the pressure-induced separation of a finely dispersed precipitate the convection becomes detectable as concentric rolls that are typical for a Rayleigh-Bénard instability. An interesting detail is the fact that larger drops are concentrated in regions where the flow is directed to the colder (i.e. upper) window; this is schematically demonstrated in Fig. 7.

After several minutes, however, a rather regular hexagon-like pattern such as shown in Fig. $8 \mathrm{~b}$ can develop (ref. 28, 31). Systematic investigations have shown that structures of this kind are produced by parallel temperature and concentration gradients along the layer; for details see ref. 28,31 .

With a modified cell the measurements on the system ethene + hexane shown in Fig. 9 have been made by Metz (ref. 32, 33). Here the temperature changes induced by the pressure jumps are measured directly in the fluid mixture with rapidly indicating thermocouples of very low heat capacity. For a pressure jump in the homogeneous region about the corresponding isentropic temperature change is found (Fig. 9a). For jumps ending in the heterogeneous range, however, considerable underpressing is possible and a kinetic limit can be interpolated where phase separation (combined with the related enthalpy and temperature effects) starts rapidly. This kinetic limit is plotted in Fig. $9 \mathrm{~b}$ and compared with the binodal curve; for a detalled discussion see ref. 32, 33. The transient temperature measurements were supplemented by parallel light scattering experiments (ref. 32, 34). Similar investigations have also been made for the formation of bubbles in pure liquids (Stein, Ief. 35).

\section{FLUID PHASE EQUILIBRIA IN BINARY SYSTEMS INVOLVING A SUPERCRITICAL COMPONENT: CLASSIFICATION BY 'FAMILIES'}

Normally the three different types of two-phase equilibrium in fluid mixtures namely liquidliquid (1l), liquid-gas ( $\mathrm{g} g$ ), and gas-gas ( $g g$ ) equilibria are discussed separately. During the last twenty-five years systematic investigations first in the author's laboratory and later additionally in other groups have shown, however, that the limits between these three forms of heterogeneous phase equilibrium are not well defined and that continuous transitions occur. This hypothesis of a continuity of all phase equilibria in fluid mixtures has been discussed in several reviews of the author where also references are given (ref. 59, 11-17, 19, 20); for experimental techniques and set-ups see e.8. ref. 16 .

Here the phenomena will only be shortly discussed starting from Fig. 10. For the type shown in Fig. 10a and $10 \mathrm{~b}$ the critical curve liquid-gas is not interrupted and runs through the usual pressure maximum. At temperatures far below the critical temperature of the pure more volatile component I separation into two liquid phases takes place additionally. The branch 11 of the critical curve corresponds to upper critical solution temperatures (UCSTs) as a function of pressure that are slightly increased with rising pressure such as found e.g. for the system pentane + methanol (see Fig. 2a).

The more the mutual miscibility of the two components decreases the more the branch 11 of the critical curve in Fig. $10 \mathrm{a}$ and $10 \mathrm{~b}$ will be displaced to higher temperatures. It can finally penetrate the ranges of temperature and pressure for the critical phenomena liquidgas ( $1 \mathrm{~g}$ ) and may pass continuously into the liquid-gas critical line $1 \mathrm{~g}$ whereas the branch 


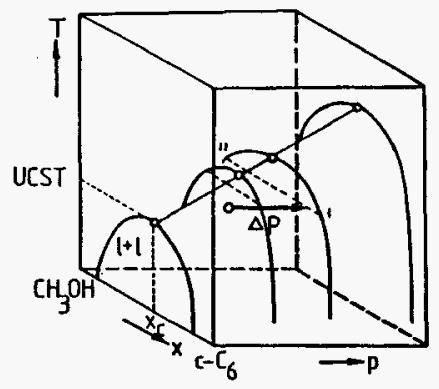

Fig. 5. Three-dimensional pTx phase diagram for cyclohexane + methanol (schematically; ref. 28; see text)

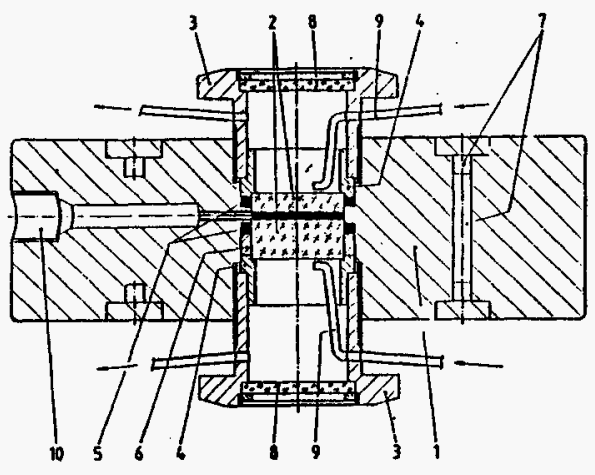

Fig. 6. Cell for pressure-jump experiments on the kinetics of phase separation in fluid mixtures (Zander, ref. 29)

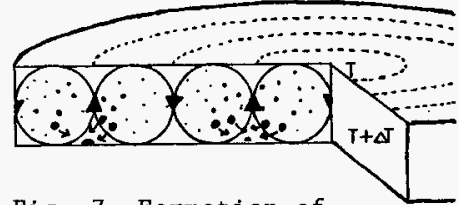

Fig. 7. Formation of convective rolls in near-isopycnic cyclohexane + methanol mixtures (Zander, ref. 29,30 ; schematically)

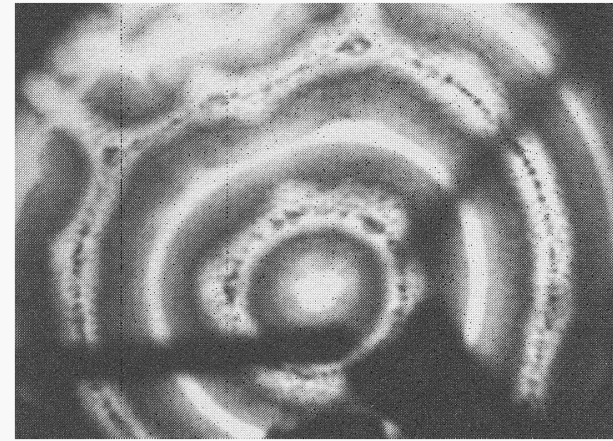

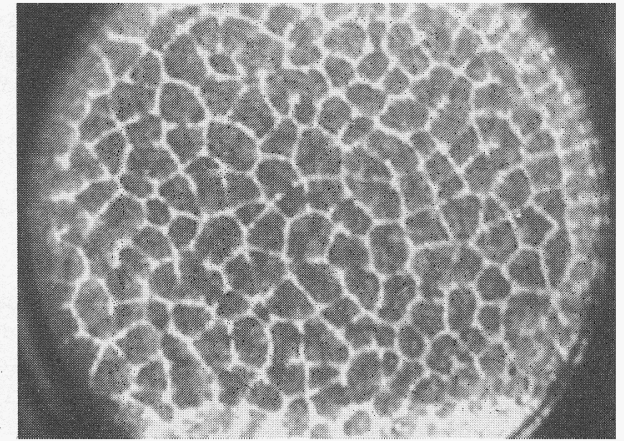

b

Fig. 8. Pressure-jump experiments on cyclohexane + methanol mixtures - Fig. 8a. Formation of convective rolls (Zander, ref. 29, 30; see text) - Fig. 8b. Formation of a dynamic hexagonal structure (Dittmann, ref. $28,30,31$ )
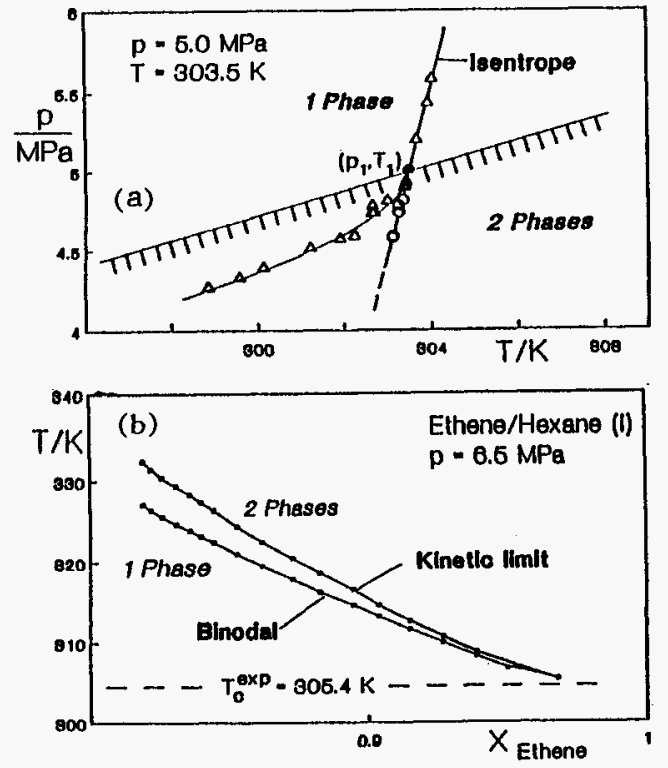

Fig. 9. (left) Pressure-jump experiments on binary ethene + hexane mixtures using transient temperature detection (Metz, ref.32-34; see text) Fig. 9a. Pressure - temperature diagram Fig. 9b. Temperature - molefraction diagram

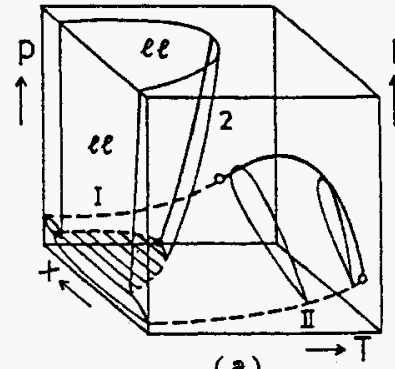

(a)

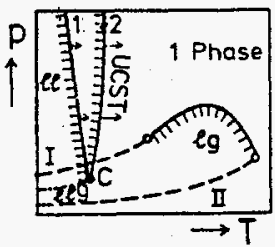

(b)

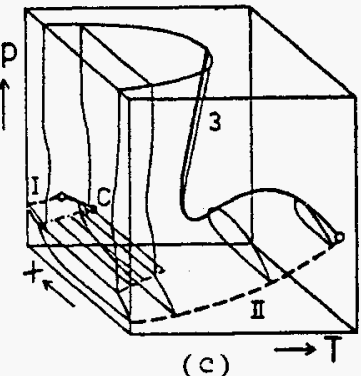

(c)

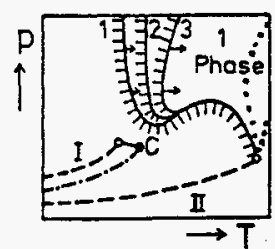

(d)
Fig. 10. pTx diagrams (upper row) and p(T) projections (lower row) for binary fluid mixtures (schematically, see text; for details and symbols used see ref.5-9,11-21) 
of the critical curve starting at the critical point CPI of pure component $I$ ends at a critical endpoint $C$ on the three-phase line liquid-liquid-gas $11 \mathrm{~g}$ (see Fig. $10 \mathrm{c}$ and $10 \mathrm{~d}$ ). In the literature the types shown in Fig. $10 \mathrm{a}$ and $10 \mathrm{~b}$ or Fig. 10c and $10 \mathrm{~d}$ are often attributed to class II or class III respectively in the classification of van Konynenburg and Scott (ref. 36, 37). Such classifications can be useful for a phenomenological discussion of the critical effects in binary mixtures but it has to be kept in mind that continuous transitions exist between the different types.

For still lower mutual miscibilities of the components critical-locus curves may be obtained such as indicated in Fig. $10 \mathrm{~d}$ by dotted lines (e.g. without any pressure maximum or minimum or running directly to increasing temperatures and pressures). Since these types are attributed to gas-gas equilibria of the second and the first kind respectively. Fig. 10 gives evidence for continuous transitions between liquid-gas, liquid-1iquid, and gas-gas equilibria.

This hypothesis was very successful and could be verified by studying series of binary systems where one constant component I such as carbon dioxide, methane, ethane, ethene, water etc. was combined with a component II that was systematically altered in size, shape, structure, and/or polarity, the phrase "family" having been proposed for such a series of related binary sytems.

As an example the $p(T)$ projections of the phase diagrams of some members of the carbon dioxide family are represented in Fig. 11. Here the fluid phase behaviour of the system $\mathrm{CO}_{2}$ + octane corresponds to the type of Fig. $10 \mathrm{a}$ and $10 \mathrm{~b}$ (class II system) whereas $\mathrm{CO}_{2}+$ hexadecane and $\mathrm{CO}_{2}+2,6,10,15,19,23$-hexamethyltetracosane (squalane) belong to type $3^{2}$ in Fig. $10 \mathrm{c}$ and $10 \mathrm{~d}\left\{\mathrm{class}\right.$ III systems) and $\mathrm{CO}_{+}+$tridecane corresponds to a transition type (ref. 38). For the $\mathrm{CHF}_{3}$ family presented in ${ }^{2} \mathrm{Fig} .12$ the transition from class II to class II critical behaviour ${ }^{3}$ is found between $\mathrm{CHF}_{3}+$ hexane and $\mathrm{CHF}_{3}+$ octane (ref. 39,40 ). Several families have also been studied by other authors e.g. Franck (ref. 2) and Brunner (ref. 53).

A part of the critical $p(T)$ curve of the binary system $\mathrm{CO}_{2}$ + hexadecane already shown in Fig. 11 is again plotted in Fig. 13 a and in addition that of ${ }^{2} \mathrm{CO}_{2}+1$-dodecanol which belongs to the same type (class III) but exhibits a lower mutual miscibility at temperatures below $400 \mathrm{~K}$. Isobaric $\mathrm{T}(\mathrm{w})$ sections ( $w=$ mass fraction) for $p=$ const $=25 \mathrm{MPa}$ ( 1 .e. an isobaric section just below the pressure minimum on the critical curve of $\mathrm{CO}_{2}+1$-dodecanol) and for $\mathrm{p}=$ const $=15 \mathrm{MPa}$ (i.e. an isobaric section below the pressure minima of the critical $p(T)$ curves of both binary systems) are represented in Fig. 13b and $13 \mathrm{c}$ respectively (ref. 41, 42). They are characteristic for such systems and will play an important role in the discussion of the ternary system $\mathrm{CO}_{2}+1$-dodecanol + hexadecane in Section 5 .

In practical applications the knowledge of the concentrations of the coexisting phases is more important than that of the corresponding mass or mole fractions since distribution coefficients and separation factors are more informative if given in concentrations. As an example in Fig. 14 the phase equilibria of binary 2-hexanol $+\mathrm{CO}_{2}$ mixtures at a constant temperature are shown in an 1sothermal $p\left(10 g \mathrm{c}\right.$ ) diagram (where $c^{2}=$ concentration e.g. in $\mathrm{mg} \cdot \mathrm{cm}^{-3}$ ) such as determined from near-infrared spectroscopy (NIR) by Friedrich (ref. 43, 44). The apparatus and the measuring technique have been described elsewhere (ref. 16, 43, 44). With the use of an integrated form of Lambert-Beer's law the total alkanol concentration $c$ was determined from the first overtone of the C-H stretching (1655-1790 $\mathrm{nm}$ ) and the combination (2220-2370 nm) modes whereas the monomer concentration $c$ was obtained from the first overtone of the $\mathrm{O}-\mathrm{H}$ stretching vibration, the difference $\mathrm{m}^{\mathrm{n}}$ both corresponding to the concentration of associated alkanol species $c$. In Fig. 14 the total pressure $p$ is plotted separately against $\log c$, $\log c$, and $\log c$ both in the coexisting gaseous and liquid phases at $362.8 \mathrm{~K}$. 'ft is an 'mn'eresting result that in the gaseous phase $c$ mon $>c$ ass whereas in the liquid phase $c_{\text {mon }}<c_{\text {ass }}$; for details and additional
results see ref. 43 , 44 .

\section{TERNARY AND QUATERNARY SYSTEMS INVOLVING A SUPERCRITICAL COMPONENT: COSOLVENCY AND APPEARANCE OF MISCIBILITY WINDOWS}

Systems consisting of three and more components (amongst them at least one supercritical) are not only interesting for basic research but also for some important applications e.g. in Supercritical Fluid Extraction (SFE) and Supercritical Fluid Chromatography (SFC).

In the following four important cases are considered:

(1) a ternary system where a low-volatile component is dissolved in a supercritical binary mixture consisting of supercritical $\mathrm{CO}_{2}$ and a second solvent gas (e.g. ethane, nitrogen etc.),

(2) a ternary system where a low-volatile component is dissolved in a supercritical solvent (e.g. $\mathrm{CO}_{2}$ ) with the addition of a socalled entrainer that improves the mutual miscibility (e.g. ethanol, acetone, dioxane etc.), 

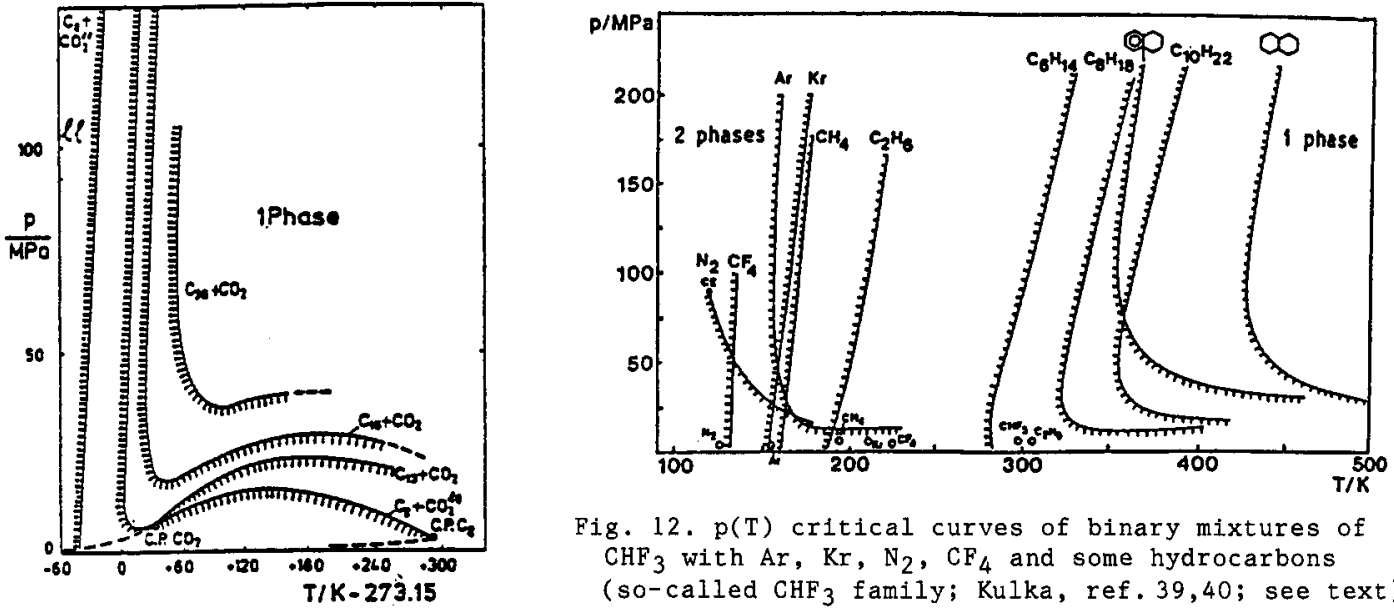

Fig. 12. $p(T)$ critical curves of binary mixtures of $\mathrm{CHF}_{3}$ with $\mathrm{Ar}, \mathrm{Kr}, \mathrm{N}_{2}, \mathrm{CF}_{4}$ and some hydrocarbons

(so-called $\mathrm{CHF}_{3}$ family; Kulka, ref. 39,40 ; see text)

Fig. 11. $p(T)$ critical curves of binary mixtures of carbon dioxide with octane, tridecane, hexadecane and $2,6,10,15,19$, 23-hexamethyltetracosane (squalane) respectively (socalled $\mathrm{CO}_{2}$ family; ref. 11-21; see text)
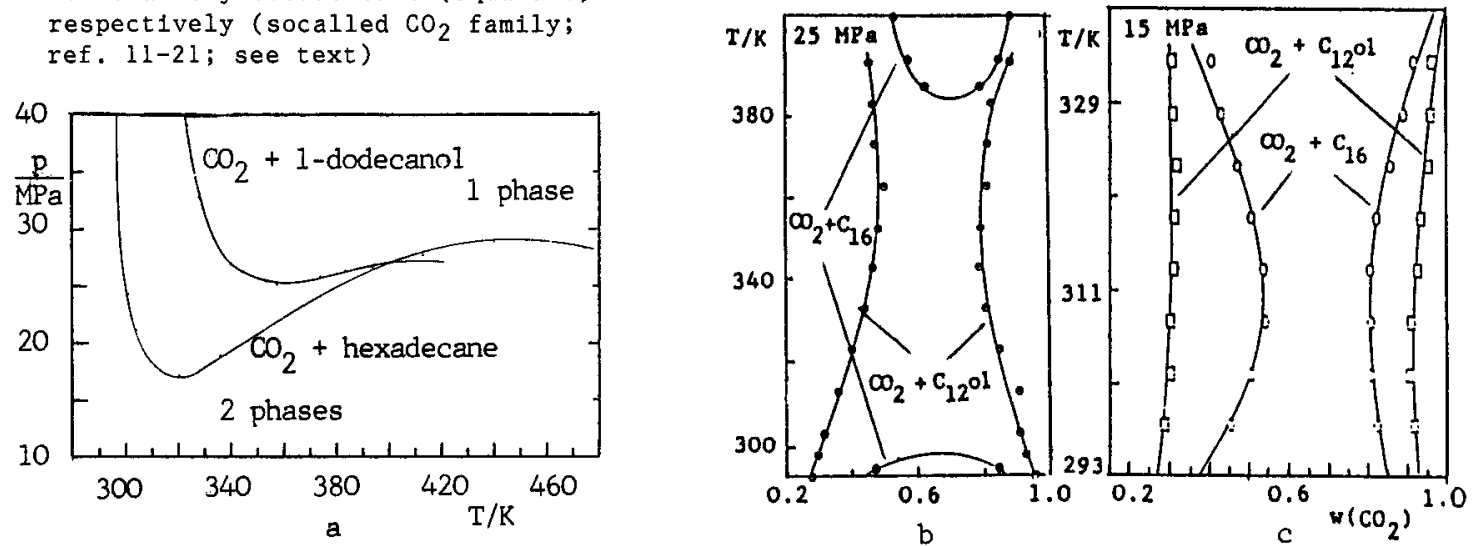

Fig. 13. Fluid-phase equilibria of the binary systems $\mathrm{CO}_{2}+1$-dodecanol $\left(\mathrm{CO}_{2}+\mathrm{Cl201}\right)$ and $\mathrm{CO}_{2}+$ hexadecane $\left(\mathrm{CO}_{2}+\mathrm{Cl} 16\right)$ (Spee, Kordikowski; ref. 41,42,51)-Fig. 13a. p(T) critical curves - Fig. 13b. T(w) isobars at $25 \mathrm{MPa}$ - Fig. 13c. T(w) isobars at $15 \mathrm{MPa}$

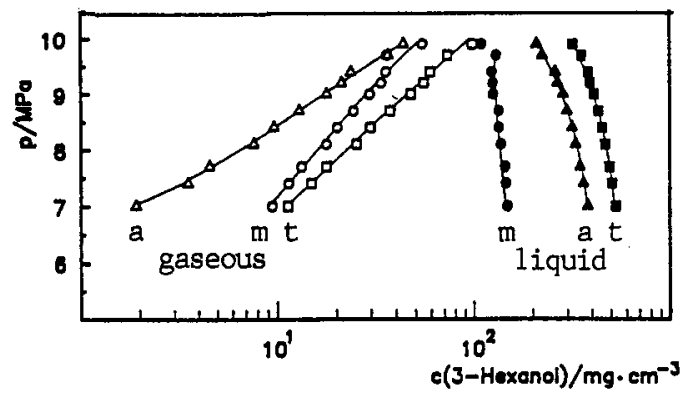

Fig. 14. $p(c(3-$ hexanol $))$ isotherms at $362.8 \mathrm{~K}$ of the system 3 -hexanol $+\mathrm{CClF}_{3}$ determined from near-infrared (NIR) spectroscopy (m = monomer, $a$ = associated, $t=$ total;

Friedrich, ref. 43, 44)

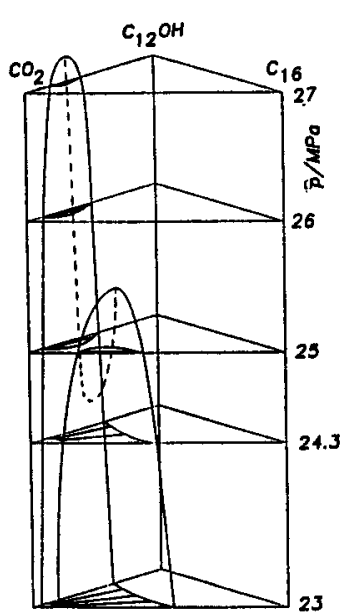

(a)

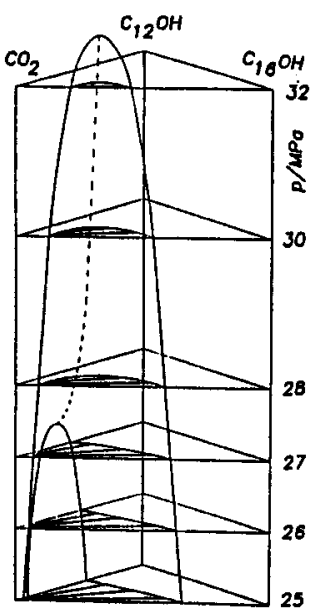

(b)
F1g. 15. Isothermal $p\left(w_{1}, w_{2}\right)$ phase prisms at $393.2 \mathrm{~K}$ (Holscher et al., ref. 49,50 : Spee, ref. 41, 42)

a. $\mathrm{CO}_{2}+1$-dodecanol + hexadecane

b. $\mathrm{CO}_{2}+1$-dodecanol +1 -hexadecanol 
(3) a ternary system where two low-volatile components are dissolved in one pure supercritical solvent $\left(\mathrm{e}, \mathrm{g} . \mathrm{CO}_{2}\right)$ and

(4) a quaternary system of the type supercritical solvent + component I + component II + moderator that can be considered as a model system to study moderator effects on solubility and selectivity of the two low-volatile components I and II in SFE.

These applications are being studied in the author's group since a long time. As an example only one model system investigated recently will be discussed in somewhat more detail in the following. It consists of $\mathrm{CO}_{2}$ (as the supercritical solvent), 1-dodecanol and hexadecane (as low-volatile components to be dissolved and separated) and 1,8-octanediol or dotriacontane (as a moderator substance) respectively.

The critical $\mathrm{p}(\mathrm{T})$ curves of the binary systems $\mathrm{CO}_{2}+1$-dodecanol and $\mathrm{CO}_{2}+$ hexadecane have already been shown in Fig. 13a; both can be attributed to class III systems according to the classification of van Konynenburg and Scott. In the experimental temperature range up to 393 $\mathrm{K} 1$-dodecanol is less soluble in $\mathrm{CO}_{2}$ than hexadecane whereas 1 -dodecanol and hexadecane are completely miscible in the liquid range.

In Fig. 15 and 16 some characteristic ternary phase diagrams are shown. The isothermal $p\left(w_{1}, w_{2}\right)$ phase prism for $T=$ const $=393 \mathrm{~K}$ in Fig. 15a (ref. 41, 42) demonstrates that here the binary critical pressures are about the same and it could be expected that the same would hold for the ternary mixtures, too. The ternary critical curve, however, runs through a distinct pressure minimum giving evidence for a socalled "cosolvency effect", i.e. a mixture of the two low-volatile components is better soluble in supercritical $\mathrm{CO}_{2}$ than each of the two components alone. Similar phenomena have been found for the solubility of one low-volatile component in a binary supercritical solvent (ref. 47-50). Besides they are quite common in polymer solutions.

The cosolvency effect found in Fig. $15 \mathrm{a}$ is also visible in the isobaric $\mathrm{T}\left(\mathrm{w}_{1}\right.$, $\left.\mathrm{w}_{2}\right)$ prism of the same system for $p=$ const $=25 \mathrm{MPa}$ in $\mathrm{Fig}$. 16a where the ternary critical curve runs through a distinct temperature maximum and minimum respectively (ref. 41, 42). The effect is even more strlking for the $\mathrm{T}\left(\mathrm{w}_{1}, \mathrm{w}_{2}\right)$ prism at $\mathrm{p}=$ const $=15 \mathrm{MPa}$ shown in Fig. $16 \mathrm{~b}$ where miscibility gaps over the whole experimental temperature range exist in the binary systems $\mathrm{CO}_{2}+1$-dodecanol and $\mathrm{CO}_{2}+$ hexadecane whereas - because of cosolvency - the ternary system exhibits a socalled "miscibility window" (ref. 51). In Fig. $17 \mathrm{~T}(\mathrm{w}$ ) sections at a constant $\mathrm{CO}_{2}$ mass fraction of $\mathrm{w}\left(\mathrm{CO}_{2}\right)=0.63$ are given for three different pressures namely $25 \mathrm{MPa}, 16$ $\mathrm{MPa}$ and $15 \mathrm{MPa}$ (ref. $41,242,51$ ) demonstrating the existence of miscibility windows at 16 and $15 \mathrm{MPa}$ respectively; here the solvent-free mass fraction of 1 -dodecanol is plotted on the abscissa.

In Fig. 15b the $\mathrm{p}\left(\mathrm{w}_{1}, \mathrm{w}_{2}\right)$ prism at $393 \mathrm{~K}$ is shown for the ternary system $\mathrm{CO}_{2}+1$-dodecanol + 1-hexadecanol (ref. 41,42 ), i.e. In comparison with the ternary system considered before hexadecane is replaced by 1 -hexadecanol. Here the binary critical pressures differ more than for the hexadecane system in Fig. 15a. Thus the effects are less spectacular but a tendency versus cosolvency is still visible from the positve curvature of the ternary critical curve.

In order to study the influence of moderators the system $\mathrm{CO}_{2}+1$-dodecanol + hexadecane was also investigated with the addition of increasing amounts of 1,8 -octanediol or dotriacontane as a moderator respectively. A detailed study of the highly complicated phase behaviour of

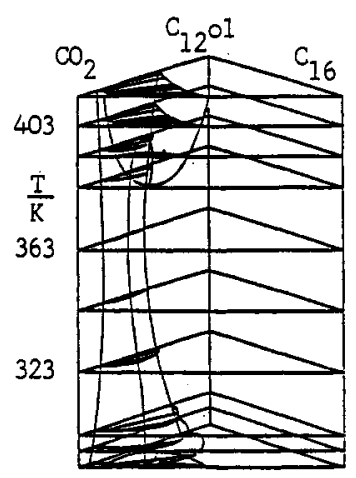

(a)

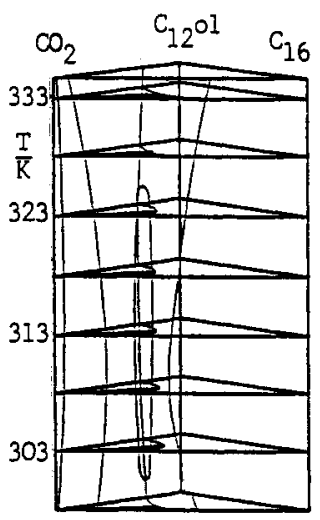

(b)

Fig. 16. Isobaric $T\left(w_{1} \cdot w_{2}\right)$ phase prisms of the ternary system $\mathrm{CO}_{2}+1$-dodecanol + hexadecane a. Isobar at $25 \mathrm{MPa}$ (Spee, ref. 41,42)

b. Isobar at $15 \mathrm{MPa}$ (Kordikowski, ref. 51)

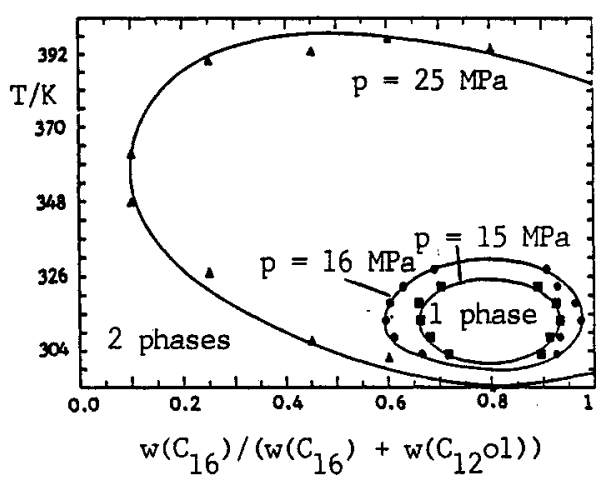

Fig. 17. $T(w(C 16) /(w(C 16)+w(C 1201)) \mathrm{sec}-$ tions through the isobaric $T\left(w_{1}, w_{2}\right)$ prisms of $\mathrm{CO}_{2}+1$-dodecanol + hexadecane at $25 \mathrm{MPa}, 16 \mathrm{MPa}$ and $15 \mathrm{MPa}$ for $\mathrm{w}\left(\mathrm{CO}_{2}\right)$ = const $=0.63$

(Spee, Kordikowski, ref. 41, 42, 51) 
the resulting quaternary systems where also tricritical phenomena have been found is given by Spee (ref. 41, 42). Here only some of his results with respect to the moderator influence on the separation factor $\alpha$ that is defined by

are presented in Fig. 18.

$$
\alpha \equiv \frac{w\left(c_{16}\right)^{g}}{w\left(c_{16}\right)^{1}} \cdot \frac{w\left(c_{12} 01\right)^{1}}{w\left(c_{12} 01\right)^{g}}
$$
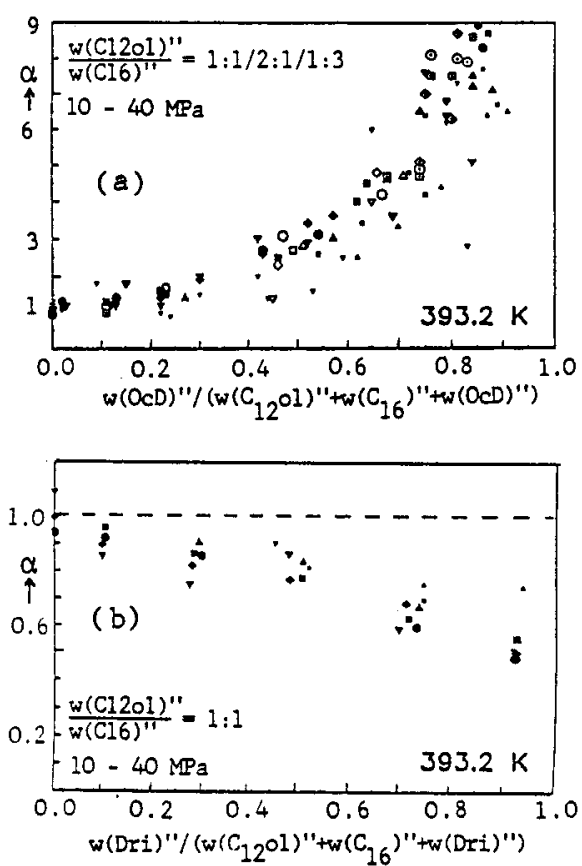

Fig. 18. Effect of moderators on the separation factor of the system 1 -dodecanol + hexadecane $+\mathrm{CO}_{2}$ at different ratios $\mathrm{w}(\mathrm{C} 1201) / \mathrm{w}(\mathrm{C} 16)$ in the liquid phase (") (393.2 K, 10-40 MPa; Spee, ref. 41,42) a. Moderator 1,8-octanedio1 b. Moderator dotriacontane

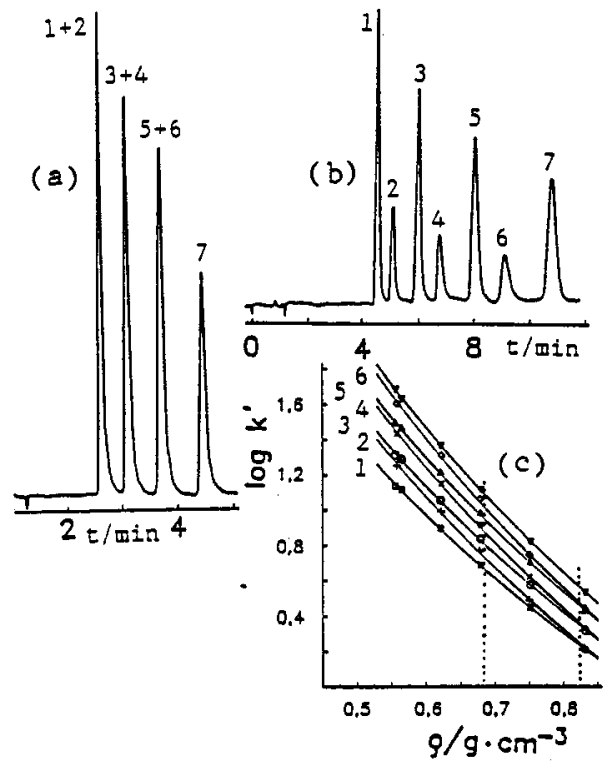

Fig. 19. SFC separations as a function of the density of the mobile phase (Wilsch, ref. 56, 58). Mobile phase: $\mathrm{CO}_{2}, 39.5^{\circ} \mathrm{C}, 1.25 \mathrm{~g} \mathrm{~min}^{-1}$. Stationary phase: Spherisorb ODS2.- Substances: Dodecyl (1), tetradecyl (3), hexadecyl (5) and octadecy1 (7) phenylether, phenylmyristate (2), phenylpalmitate (4), phenylstearate $(6)$.

a. $\rho\left(\mathrm{CO}_{2}\right)=0.82 \mathrm{~g} \cdot \mathrm{cm}^{-3}(18.1 \mathrm{MPa})$

b. $\rho\left(\mathrm{CO}_{2}\right)=0.68 \mathrm{~g} \cdot \mathrm{cm}^{-3}(10.8 \mathrm{MPa})$

c. $\log \mathrm{k}^{\prime}$ as a function of $\mathrm{p}\left(\mathrm{CO}_{2}\right)$

In Fig. 18a and $18 \mathrm{~b}$ the separation factor $\alpha$ is plotted against the solvent-free mass fraction of the moderator in the liquid phase for both cases. For the ternary system without any addition of moderator (i.e. W $=0$ ) $\alpha$ equals unity within the limits of experimental error demonstrating thaderafor supercritical solvent $\mathrm{CO}_{2}$ exhibits a high solvent power but a poor selectivity here. With the addition of a moderator, however, separation factors up to $\alpha \approx 9$ for 1,8 octanediol and down to $\alpha \approx 0.5$ for dotriacontane are found at the highest moderator mass fractions used; these values are independent on the total pressure and the ratio $\mathrm{w}\left(\mathrm{C}_{12} \mathrm{Ol}\right) / \mathrm{w}\left(\mathrm{C}_{16}\right)$ in the mixture within the experimental error in mass fraction. These effects can qualitatively be understood from the assumption that the (polar) 1-dodecanol is preferably retained in the liquid phase by the low-volatile (polar) diol and vice versa the (unpolar) hexadecane by the low-volatile (unpolar) dotriacontane (ref. 41,42 ).

These investigations that give evidence for a distinct extractive effect of carefully selected moderators in Supercritical Fluid Extraction (SFE) are continued (ref. 51).

\section{APPLICATIONS}

In the following list that is an extension of similar earlier compilations (ref. 8, 11-15, 17, 19, 20) some selected fields are given where fluid mixtures are of interest:

Mineralogy, geology:

- formation and migration of minerals; geysers, volcanos; geothermal energy; hydrothermal synthesis etc. 
Chemical reactions

- solvents with variable density, dielectric constant (permittivity), solvent power and low viscosity e.g. $\mathrm{C}_{2} \mathrm{H}_{4}, \mathrm{NH}_{3}, \mathrm{CO}_{2}$ etc.

Chemical industry

- LDPE, ammonia, methanol, acetic acid, oxo-synthesis, Fischer-Tropsch synthesis etc.

Petroleum and natural gas industries (NG, SNG)

- exploitation, separation, purification, storage, transport; tertiary oil recovery; o11 shales

Separation processes

- Supercritical Fluid Extraction (SFE) (caffeine, hops, spices, drugs, fragrances; coal, lubricants; ethanol, vegetable oils, soy beans, glycerides; tobacco expansion)

- Supercritical Fluid Chromatography (SFC) (analytical, preparative; control of SFE; physicochemical data e.g. capacity ratios, diffusion coefficients etc (see below))

Miscellaneous

- purification of adsorbents; wet air oxidation; drying of tissues; dying of fibers etc.

Since the field is in rapid development the list is incomplete.

The accent of modern activities is on Supercritical Fluld Extraction (SFE) and Supercritical Fluid Chromatography (SFC) where pure or mixed supercritical fluids (also with the addition of moderators) are used as solvents or mobile phases respectively, the most important applications on an industrial scale up to now being the decaffeination of coffee and tea and the extraction of hops. The increasing interest in this field is demonstrated by a rising number of symposia (e.g. the "International Symposium on Supercritical Fluids" held at Nice, France, in October 1988, see ref. 19), books (ref. 20, 77-82, most of them proceedings of meetings), review articles (see e.g. ref. $5,8,9,10,17,19$ ) and original papers to which the reader is referred for further details and references; at present several books on SFC are in press (e.g. ref. 21 ).

In the following some recent own applications of Supercritical Fluid Chromatography (SFC) will be treated in somewhat more detail. In SFC supercritlcal pure or mixed fluids are used as mobile phases for the separation of low-volatile and/or thermolabile compounds. SFC has become a well-established method of analysis (see e.g. references 19, 20, 21, 82, 83), and in the meantime SFC chromatographs are already widely commercialized (ref. 55).

An informative example for an SFC separation using supercritical carbon dioxide as a mobile phase is given in Fig. 19 (ref. 56-58) where SFC chromatograms for a mixture of fatty alcohol phenyl ethers and fatty acid phenyl esters are shown at two different $\mathrm{CO}_{2}$ densities. At $\rho\left(\mathrm{CO}_{2}\right)=0.82 \mathrm{~g} \cdot \mathrm{cm}^{-3}(\mathrm{Fig}, 19 \mathrm{a})$ the solvent power of the mobile phase is high resulting in small retention times $t_{r}$; the separation of the substances, however, is incomplete. At $p\left(\mathrm{CO}_{2}\right)=0.68 \mathrm{g.cm}$ (Fig. $19 \mathrm{~b}$ ) separation is good but the retention times $t_{r}$ are much longer. This situtation is typical, and in practice a compromise between selectivity and retention times $t_{r}$ (that reflect the solvent power) must be found.

From the retention time $t_{r i}$ the capacity ratio $k_{i}^{\prime}$ of a substance 1 can be calculated using Eq. (1)

$$
k_{i}^{\prime} \equiv \frac{c_{i}^{\text {stat }}}{c_{i}^{\text {mob }}} \cdot \frac{v^{\text {stat }}}{v^{\text {mob }}}=k_{i} \cdot \frac{v^{\text {stat }}}{v^{\text {mob }}}=\frac{t_{r i}-t_{0}}{t_{0}}
$$

where $c_{i}^{\text {mob }}$ and $v^{\text {mob }}$ or $c^{\text {stat }}$ and $v^{\text {stat }}$ are the concentration of a component $i$ in and the volume of the mobile (mob) or the stationary (stat) phases respectively, $k_{i} \equiv \mathrm{c}^{i} \mathrm{c}_{\mathrm{i}} / \mathrm{m}$
is the distribution coefficient of substance $i$ between the stationary and the mobile phases, $t_{r}$ the retention time of substance $i$, and $t$ the retention time of an inert component. The selectivity $\alpha_{i j}$ for the separation of two substances $i$ and $j$ is defined by

$$
\left.\alpha_{i j} \equiv k_{i} / k_{j}=k_{i}^{\prime} / k_{j}^{\prime}=\left(t_{r i}-t_{0}\right) / t_{r j}-t_{0}\right)
$$

It follows from Eq.(2) that two substances $i$ and $j$ can be separated if their capacity ratios differ sufficiently.

Log $k^{\prime}$ values obtained from Eq.(1) are plotted against $\rho\left(\mathrm{CO}_{2}\right)$ in Fig. 19c that again confirms the conflict between retention time and selectivity mentioned above. At higher densities even intersection points of some of the 1sotherms exist making the separation of the corresponding substances impossible. These dependences on density, temperature and eventually other parameters must be carefully considered in practical SFC runs. Often separation can be improved by the use of temperature and density gradients (ref. 56, 58, 59). 


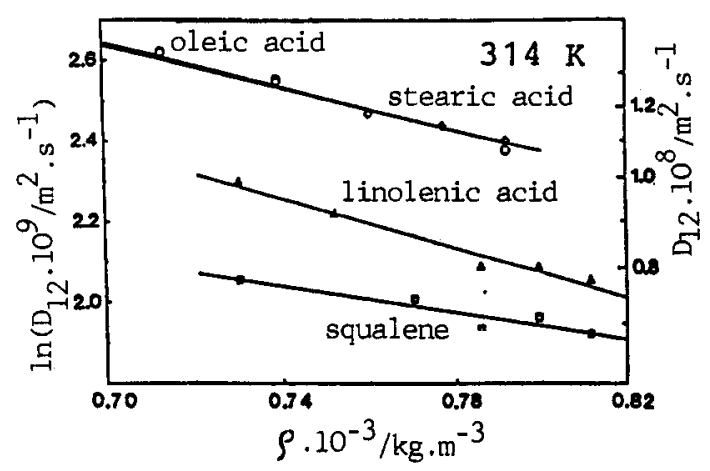

Fig. 20. In $D_{12}$ of some fatty acids and squalene in $\mathrm{CO}_{2}$ as a function of $\rho\left(\mathrm{CO}_{2}\right)$ from $\mathrm{SFC}$ experiments (Dahmen et al., ref. 65)

The capacity ratio $k_{i}^{\prime}$ is also of interest from a thermodynamic point of view. Since it is proportional to the distribution coefficient $k_{1}$, the well-known description of $k_{i}$ by equilibrium thermodynamics can also be applied to $k_{i}^{\prime}$; for a detailed discussion see ${ }^{i} . g$. ref. 10,56 .

Whereas the capacity ratio $k_{i}^{\prime}$ is only determined by the position of the chromatographic peak of substance $i$ ( $i . e$. the retention time $t$ ) in a packed or capillary column, the binary diffusion coefficient $D_{1}$ of a component $i$ at infinite dilution in a supercritical solvent 1 (e.g. $\mathrm{CO}_{2}$ ) can be obtained from the shape of the chromatographic peak of substance $i$ in a long void column using component 1 as a moblle phase. With some important assumptions that are discussed in detail elsewhere (ref. 60-65) $\mathrm{D}_{11}$ can be obtained from Eq. (3) and (3a)

$\begin{aligned} \text { HETP } . L & =\sigma(z)^{2}=2 \cdot D_{\text {eff }} \cdot t_{r i}=2 \cdot D_{\text {eff }} \cdot L / \bar{v} \\ \text { with } \quad D_{\text {eff }} & =D_{1 i}+\left(r_{0}^{2} \cdot \bar{v}^{2}\right) /\left(48 D_{l i}\right)\end{aligned}$

where $\sigma(z)^{2}$ is the variance of the (Gaussian) peak of substance $i$ in length units, HETP the height equivalent to a theoretical plate, $D$ the effective binary diffusion coefficient, $D_{1}$ the binary diffusion coefficient (here at infinite dilution of substance $i$ in component 1), $r$ the internal radius and $L$ the length of the void column, and $\bar{v}$ the mean velocity of the mobile phase.

Systematic measurements on many substances in different solvents have been made in the author's laboratory in order to determine $D_{1}$ values as a function of temperature, pressure, and density of the mobile phase (ref. 10, 60-65). These data are of considerable interest for the understanding of mass transfer in SFE and SFC. Some recent data are given in Fig. 20 $(i=2$; see ref. 65). It is remarkable that stearic acid and oleic acid (with one double bond in the chain) have about the same $D_{12}$ values whereas $D_{12}$ is considerably smaller for linolenic acid (having three double bonds in the chain) and squalene (having six double bonds in the chain and a considerably higher molar mass). The data indicate that higher stiffness of the molecule and higher molar mass result in lower $D_{12}$ values; for detalls and a discussion of the significance of an effective molecular radius using a general form of the Stokes-Einstein equation see e.g. ref. 65 .

\section{PHASE TRANSITIONS IN LIQUID CRYSTALS}

In addition to temperature. and additives, pressure is an important parameter to influence order and polymorphism of a liquid crystal. Therefore high pressure studies on liquid crystals have become of growing interest during the last decade; for a state-of-the-art review till 1979 see Chandrasekhar and Shashidhar (ref. 66).

Systematic investigations on the polymorphism of some selected thermotropic liquid crystals have been performed in the author's laboratory as a function of pressure up to about 2 GPa using differential thermal analysis (DTA) and diamond anvil cell (DAC) techniques. For the DTA measurements the sample under test is enclosed in a gas-tight indium or lead capsule and heated linearily under different gas pressures in a high-pressure autoclave. In DAC the sample is squeezed between two diamond windows using a gasket support and observed through a polarizing microscope, pressure being determined by the socalled ruby fluorescence method. For details of the methods see ref, $68-70$ and ref. $68,73-75$ respectively; because of the relatively high temperatures involved the ruby fluorescence method had to be improved in the present work (ref. 73,74 ).

In the study of liquid crystals DTA and DAC are complementary methods: With DAC in addition to first order transformations phase transitions of higher order also at very high pressures can be observed that are not detectable in DTA whereas first order transition temperatures determined as a function of pressure by DTA represent data at relatively low pressures that 


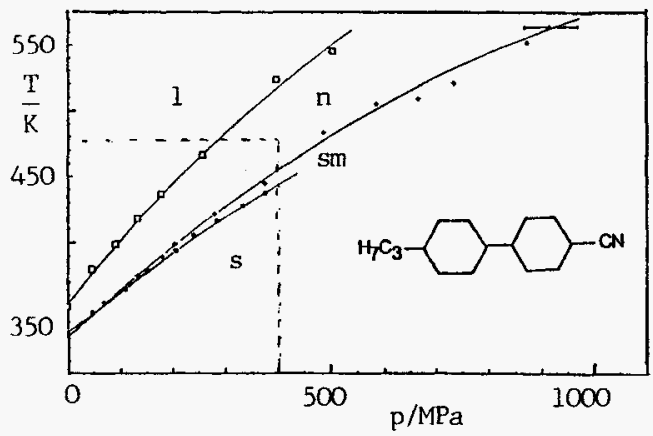

Fig. 21. $p(T)$ phase diagram of the liquid crystal trans, trans-4-n-propy1-4'-cyanobicyclohexane (3CCH) from DTA (Bartelt, ref. 69,71) and DAC (Kleemann, ref. 75) experiments

(a)

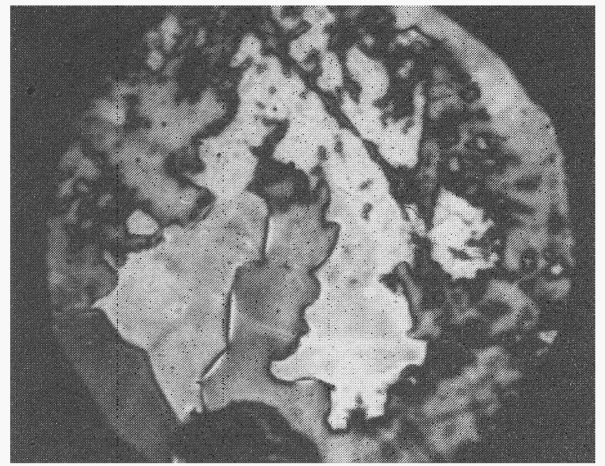

(b)

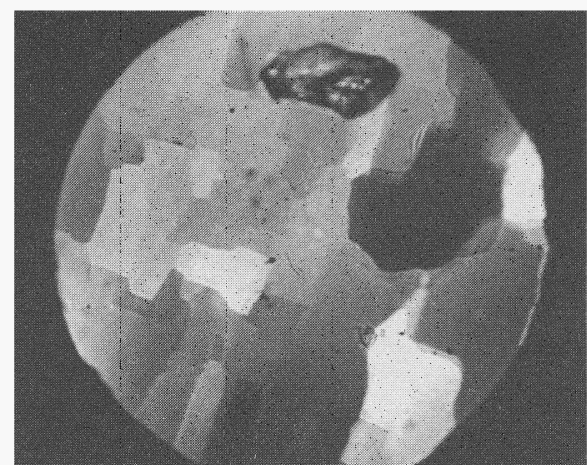

Fig. 22. Textures of the liquid crystal trans,trans-4-n-propyl-4'-cyanobicyclohexane (3CCH) from DAC experiments under high pressure (Kleemann, ref. 75)

a. Nematic phase $(527 \mathrm{~K}, 800 \mathrm{MPa}) \quad$ b. Smectic phase $(463 \mathrm{~K}, 450 \mathrm{MPa})$

can additionally be used for the pressure calibration of the DAC equipment. In these measurements the stability ranges of nematic, smectic and solid phases of some selected liquid crystals have been determined and a whole pattern of high-pressure phenomena has been observed e.g. pressure-induced as well as pressure-limited phases, tricritical points, reentrant phenomena etc. For reviews of the own results and some more recent own publications in this field see ref, 67-72 and ref, 73-75 respectively to which the reader is referred for details.

In the following only one characteristic example will be considered in somewhat more detail. In Fig. 21 the $p(T)$ phase diagram of the thermotropic liquid crystal trans,trans-4-n-propyl4'-cyanobicyclohexane(3CCH) up to about $2 \mathrm{GPa}$ is shown. The data have been obtained from DTA experiments up to about $800 \mathrm{MPa}$ (Bartelt, ref. 69, 71) and from DAC investigations in the whole experimental pressure range up to about $2 \mathrm{GPa}$ (Kleemann, ref. 75). The results confirm the usual increase of the nematic range with rising pressure and give evidence for a stable pressure-induced smectic phase above a triple point nematic/smectic/solid at about $360 \mathrm{~K}$ and $80 \mathrm{MPa}$. Both the nematic and the smectic phases could be identified by their textures measured under pressure (see Fig. 22a and 22b). Thus Fig. 22 corresponds to one of the extremely rare cases where textures have been observed directly under high pressure. Because of its fascinating structures and colours (that are unfortunately not visible in the reproduction) it is at the same time an example for the beauty of the world of liquid crystals and science as a whole.

\section{OUTLOOK}

It has been shown in Section 6 that fluid mixtures are of considerable importance in many fields of science and industry.

For some large-scale high-pressure processes in industry (e.g. oxo synthesis, LDPE), the importance of highly compressed fluid mixtures will probably decrease already in the near future since efforts are made to apply lower or even normal pressures (e.g. by using better catalysts) in order to save compression costs. The interest in fluid mixtures with respect to geothermal energy production, tertiary oil recovery, gasification and liquefaction of coal etc, however, will increase considerably. For (relatively small scale) extractions corresponding to rather expensive products (e.g. decaffeinated coffee and tea, hops, drugs, spices, fragrances etc) Supercritical Fluid Extraction (SFE) will remain a promising technique; here the legal situation (e.g. future prohibition of organic solvents in the food and pharmaceutical industries) will be of primary importance. It is not necessary to accentuate the progress here that might be obtained from a further development and application of liquid crystals. 
Therefore investigations on fluid systems such as treated in the present review as a function of temperature, pressure, composition and other parameters are and will remain to be a challenge to experiment, theory and application at least during the next decade.

\section{Acknowledgement}

The author thanks the IUPAC Commission on Thermodynamics for having been elected Rossini Lecturer at the 11th IUPAC Conference on Chemical Thermodynamics at Como, Italy, in August 1990. He expresses his gratitude to his collaborators at the University of Bochum who have contributed to the more recent and mostly unpublished results presented here; these are

- Dr. J. Friedrich, U. Grasedieck, J. Haarhaus, A. Kordikowski, Dr. J. Kulka, H. Ochel, Dr.

J. Quednau, Dr. M. Spee a.o. with respect to the work on liquid and fluid mixtures,

- M. Dittmann, Dr. U. Metz, R. Zander a.o. concerning the pressure-jump relaxation experiments,

- N. Dahmen, A. Dulberg, A. Kordikowski, Dr. A. Wilsch a.o. with respect to the investigations on Supercritical Fluid Chromatography (SFC), and

- Dr. A. Bartelt, J. Kleemann, Dr. A. Rothert a.o. for the measurements on liquid crystals.

Financial support of the Deutsche Forschungsgemeinschaft (DFG), the Bundesminister fur Forschung und Technologie der Bundesrepublik Deutschland (BMFT) (through the Deutsche Agentur fur Raumfahrt-Angelegenheiten (DARA) $\mathrm{GmbH}$ ), the Minister fur Wissenschaft und Forschung (MWF) des Landes Nordrhein-Westfalen, and the Fonds der Chemischen Industrie e.V. is gratefully acknowledged.

\section{REFERENCES}

1. M.L. McGlashan, Pure Appl. Chem. 57, 89-103 (1985); J. Chem. Thermodynamics 17, $301-319$ (1985).

2. E.U. Franck, Pure Appl. Chem. 59, 25-34 (1987); J. Chem. Thermodynamics $\underline{19}$, 225-242 (1987).

3. K.S. Pitzer, Pure App1. Chem. 61, 979-988 (1989); J. Chem. Thermodynamics 21, 1-17 (1989).

4. G.M. Schneider, Thermochimica Acta 88, 159-168 (1985); U. Wenzel and G.M. Schneider, Thermochimica Acta 109, 111-119 (1986).

5. G.M. Schneider, Ber. Bunsenges. Phys. Chem. 70, 497-520 (1966).

6. G.M. Schneider, Adv. Chem. Phys. 17, 1-42 (1970).

7. G.M. Schneider, in F. Franks (ed): Water - A Comprehensive Treatise, Vol. 2, Plenum Press, New York 1973; Chap. 6, p. 381-404.

8. G.M. Schneider, Angew. Chem. 90, 762-774 (1978); Angew. Chem. Int. Ed. Engl. 17, 716-727 (1978).

9. G.M. Schneider, in M.L. McGlashan (ed): Chemical Thermodynamics, Vol. 2, A Specialist Periodical Report, London, 1978, Chap. 4, p. 105-146.

10. U. van Wasen, I. Swaid and G.M. Schneider, Angew. Chem. 92, 585-598 (1980); Angew. Chem. Int. Ed. Engl. 19, 575-587 (1980).

11. G.M. Schneider, in Rheinisch-Westfalische Akademie der Wissenschaften: Lectures N301, Westdeutscher Verlag 1981 , p. 7-49.

12. G.M. Schneider, Fluid Phase Equil. 10, 141-157 (1983).

13. G.M. Schneider, Pure Appl. Chem. 55, 479-492 (1983).

14. G.M. Schneider, Ber. Bunsenges. Phys. Chem. 88, 841-848 (1984).

15. G.M. Schneider, Thermochimica Acta 88, 17-34 (1985).

16. U.K. Deiters and G.M. Schnelder, Fluid Phase Equil. 29, 145-160 (1986).

17. G.M. Schneider, in M. Hirata and T. Ishikawa (eds): The Theory and Practice in Supercritical Fluid Technology, NTS, Tokyo, 1987, p. 3-37.

18. G.M. Schneider, J. Ellert, U. Haarhaus, I.F. Holscher, G. Katzenski-Ohling, A. Kopner, J. Kulka, D. Nickel, J. Rubesamen and A. Wilsch, Pure Appl. Chem. 59, 1115-1126 (1987).

19. G.M. Schneider, in M. Perrut (ed): Proceedings of the International Symposium on Supercritical Fluids, October 17-19, 1988, Nice (France), p. 1-17.

20. G.M. Schneider, E. Stahl and G. Wilke (eds): Extraction with Supercritical Gases, Verlag Chemie, Weinheim, $1978 ; 189$ pages.

21. B. Wenclawiak (ed): Supercritical Fluids in Analytical Chemistry, Springer, Berlin, Heldelberg, New York, London, Paris, Tokyo, Hong Kong, in press.

22. Achema-Jahrbuch 91, Vol. 1, Forschung und Lehre des Chemie-Ingenieurwesens, Dechema, Frankfurt, 1990.

23. U. Haarhaus and G.M. Schneider, J. Chem. Thermodynamics 20, 1121-1129 (1988).

24. U. Grasedieck, diploma thesis, University of Bochum, FRG, 1988 .

25. G. Schneider, Z. physik. Chem. Frankfurt 39, 187-197 (1963).

26. J. Quednau, doctoral thesis, University of Bochum, FRG, 1988.

27. H. Ochel, diploma thesis, University of Bochum, FRG, 1990.

28. G.M. Schneider, M. Dittmann, U. Metz and J. Wenzel, Pure Appl. Chem. 59, 79-90 (1987).

29. R. Zander, M. Dittmann and G.M. Schneider, Z. Naturforsch. 45a, 1309-1316 (1990).

30. R. Zander, M. Dittmann and G.M. Schneider, Proceedings of the VIIth European Symposium on Materials and Fluid Sciences in Microgravity, Oxford, UK, 10-15 September 1989, ESA SP-295 (January 1990), p. 247-251. 
31. M. Dittmann and G.M. Schneider, Z. Naturforsch. 4la, 678-680 (1986).

32. U. Metz, doctoral thesis, University of Bochum, FRG, 1989.

33. U. Metz and G.M. Schneider, Ber. Bunsenges. Phys. Chem. 94, 452-456 (1990).

34. U. Metz and G.M. Schneider, Ber. Bunsenges. Phys. Chem. 94, 447-452 (1990).

35. J. Stein, diploma thesis, University of Bochum, FRG, 1990 .

36. P.H. van Konynenburg and R.L. Scott, Ph1l. Trans. Roy. Soc. (London) 298, 495 (1980).

37. J.S. Rowlinson and F.L. Swinton: Liquids and Liquid Mixtures, 3rd ed., Butterworths, London, 1982; 328 pages.

38. Th.W. de Loos, W. Poot and J. de Swaan Arons, Proceedings of the llth IUPAC Conference on Chemical Thermodynamics, Como, Italy, August 26-31, 1990; p. 238.

39. J. Kulka, doctoral thesis, University of Bochum, FRG, 1990.

40. J. Kulka and G.M. Schneider, High Pressure Research 4, 601-603 (1990); Fluid Phase Equil., 63, 111-128 (1991).

41. M. Spee, doctoral thesis, University of Bochum, FRG, 1990.

42. M. Spee and G.M. Schneider, High Pressure Research 5, 675-677 (1990); Fluid Phase Equ11., 65, 263-271 (1991).

43. J. Friedrich, doctoral thesis, University of Bochum, FRG, 1988.

44. J. Friedrich and G.M. Schneider, J. Chem. Thermodynamics 21, 307-319 (1989).

45. R. Konrad, doctoral thesis, University of Bochum, FRG, 1982 .

46. R. Konrad, I. Swaid and G.M. Schneider, Fluid Phase Equil. 10, 307-314 (1983).

47. G. Katzenski-Ohling, doctoral thesis, University of Bochum, FRG, 1986.

48. G. Katzenski-Ohling and G.M. Schneider, Fluid Phase Equil. 34, 273-286 (1987).

49. I.F. Holscher, doctoral thesis, University of Bochum, FRG, 1988.

50. I.F. Holscher, M. Spee and G.M. Schneider, Fluid Phase Equil. 49, 103-113 (1989).

51. A. Kordikowski, doctoral thesis, University of Bochum, FRG, in preparation.

52. G. Brunner and S. Peter, Chem. Ing.-Techn. 53, 529-542 (1981).

53. E. Brunner, J. Chem. Thermodynamics 22, 335-353 (1990) (with references of earlier work).

54. V.A. Mazur and L.Z. Boshkov, Dokl. Akad. Nauk SSSR 294, 901 (1987)

55. Nachr. Chem. Tech. Lab. 36 (special issue on chromatography), 93-100 (1988).

56. A. Wilsch, doctoral thesis, University of Bochum, FRG, 1985.

57. A. Wilsch and G.M. Schneider, Fresenius Z. Anal. Chem. 316, 265-267 (1983).

58. A. Wilsch and G.M. Schneider, J. Chromatogr. 357, 239-252 (1986).

59. K.H. Linnemann, A. Wilsch and G.M. Schneider, J. Chromatogr. 369, 39-48 (1986).

60. I. Swald and G.M. Schneider, Ber. Bunsenges. Phys. Chem. 83, 969-974 (1979).

61. R. Feist and G.M. Schneider, Sep. Sc1. Technol. 17, 261-270 (1982).

62. A. Wilsch, R. Feist and G.M. Schneider, Fluid Phase Equi1. 10, 299-306 (1983).

63. A. Kopner, A. Hamm, J. Ellert, R. Feist and G.M. Schneider, Chem. Eng. Sci. 42, 22132218 (1987).

64. N. Dahmen, A. Dulberg and G.M. Schneider, Ber. Bunsenges. Phys. Chem. 94, 384-386, 710 (1990).

65. N. Dahmen, A. Kordikowski and G.M. Schneider, J. Chromatogr. 505, 169-178 (1990).

66. S. Chandrasekhar and R. Shashidhar, in G.H. Brown (ed): Advances in Liquid Crystals, Vol. 4, Academic Press, London, 1979.

67. J. Herrmann, H.D. Kleinhans and G.M. Schneider, J. Chim. Phys. Phys. Chim. Biol. 80, $111-117$ (1983).

68. G.M. Schneider, A. Bartelt, J. Friedrich, H. Reisig and A. Rothert, Physica 139\& 140B, 616-625 (1986)

69. A. Bartelt, doctoral thesis, University of Bochum, FRG, I988.

70. A. Bartelt and G.M. Schneider, Rev. Sci. Instr. 60, 926-929 (1989).

71. A. Bartelt and G.M. Schneider, Mol. Cryst. Liq. Cryst. 173, 75-84 (1989).

72. A. Bartelt, J. Rubesamen and G. M. Schneider, High Pressure Research 3, 288-290 (1990).

73. A. Rothert, doctoral thesis, University of Bochum, FRG, 1989.

74. A. Rothert and G.M. Schneider, High Pressure Research 3, 285-287 (1990).

75. J. Kleemann, doctoral thesis, University of Bochum, FRG, in preparation.

76. U.K. Deiters in K.C. Chao and R.L. Robinson (Eds): ACS Symposium Series No.300 Equations of State: Theories and Applications, American Chemical Society 1986.

77. E. Stahl, K.W. Quirin and D. Gerard: Verdichtete Gase zur Extraktion und Raffination, Springer, Berlin, Heidelberg, New York, Paris, Tokyo, 1987.

78. M. Mctugh and V. Krukonis: Supercritical Fluid Extraction - Principles and Practice, Butterworths, 1986 .

79. T.G. Squires and M.E. Paulaitis (eds): Supercritical Fluids - Chemical and Engineering Principles and Applications, ACS Symposium Series 329, American Chemical Society, Washington, DC, 1987.

80. B.A. Charpentier and M.R. Sevenants (eds): Supercritical Fluid Extraction and Chromatography - Techniques and Applications, ACS Symposium Series 366, American Chemical Society, washington, DC, 1988.

81. K.P. Johnston and J.M.L. Penninger (eds): Supercritical Fluid Science and Technology, ACS Symposium Series 406, American Chemical Society, 1989.

82. R.M. Smith: Supercritical Fluid Chromatography, The Royal Society of Chemistry, London, 1988 .

83. C.M. White (ed.): Modern Supercritical Fluid Chromatography, Huthig, Heidelberg, Basel, New York, 1988. 